BULLETIN Bulletin hispanique

HISPANIQUE Université Michel de Montaigne Bordeaux

$115-2$ | 2013

Les traductions vieillissent-elles ?

\title{
Simone de Beauvoir en català
}

\section{Pilar Godayol}

\section{(2) OpenEdition}

\section{Journals}

Edición electrónica

URL: http://journals.openedition.org/bulletinhispanique/2856

DOI: 10.4000/bulletinhispanique.2856

ISSN: $1775-3821$

\section{Editor}

Presses universitaires de Bordeaux

\section{Edición impresa}

Fecha de publicación: 28 diciembre 2013

Paginación: 669-684

ISBN: 978-2-86781-908-7

ISSN: 0007-4640

Referencia electrónica

Pilar Godayol, « Simone de Beauvoir en català », Bulletin hispanique [En línea], 115-2 | 2013, Publicado

el 14 febrero 2017, consultado el 20 abril 2019. URL : http://journals.openedition.org/

bulletinhispanique/2856 ; DOI : 10.4000/bulletinhispanique.2856 


\title{
Simone de Beauvoir en català ${ }^{1}$
}

\author{
Pilar Godayol \\ Universitat de Vic
}

Simone de Beauvoir fut avec Betty Friedan une des premières théoriciennes du féminisme à arriver en Catalogne dans les années soixante. Cet article décrit la réception de Simone de Beauvoir en catalan et plus particulièrement l'influence exercée par Le deuxième sexe.

Mots-clés : histoire de la traduction, genre et traduction, Simone de Beauvoir, traduction en catalan.

Con Betty Friedan, Simone de Beauvoir fue una de las primeras pensadoras feministas que llegaron a Cataluña en los años sesenta. Este artículo da cuenta de la recepción al catalán de Simone de Beauvoir y se fija especialmente en la influencia de El segundo sexo.

Palabras claves: historia de la traducción, género y traducción, Simone de Beauvoir, Beauvoir traducida al catalán.

Along with Betty Friedan, Simone de Beauvoir was one of the first feminist thinkers to be read in Catalonia during the sixties. This article deals with the Catalan language reception of Simone de Beauvoir and, in particular, the influence of 'The Second Sex'.

Keywords: history of translation, gender and translation, Simone de Beauvoir, Beauvoir translated into Catalan.

1. Aquest article s'inscriu en el grup d'investigació consolidat «Estudis de gènere: traducció, literatura, història i comunicació» (GETLIHC) de la Universitat de Vic (AGAUR, SGR-833) i en el subprojecte I+D «Traductoras y traducciones en la Cataluña contemporánea (1939-2000)» (Ref.: FFI2010-19851-C02-02), finançat pel Ministerio de Ciencia e Innovación. 
Simone de Beauvoir va néixer a París el 9 de gener de 1908. És difícil d'explicar la seva vida. És difícil de parlar d'algú que ens ha contat tants moments, tants detalls de la pròpia existència. Ens és impossible, tot llegint els tres volums de les seves Memòries de no cedir a la temptació de portar-li la contrària, com fem amb un amic que tracta d'explicar-nos, tot justificant-se, els seus últims entrebancs, i contradir-lo per conèixer-lo millor, per col-laborar a la veritat d'allò que ens explica. [...]

Simone de Beauvoir, la privilegiada, neix en un univers ordenat. Neix en una família de classe mitjana, prou rica per a viure bé, prou modesta per a no haver de tenir mala consciència, en un país en què la intel-ligència es cotitza a molt alt preu, en què tot és previsible i s'esdevé per a major honra i glòria de la humanitat. Amb tot, la noia de casa bona es desempallega d'aquest univers segur ben moblat, i emprèn l'aventura de viure amb una sola exigència: ésser conscient, exigir de si mateixa la màxima lucidesa, la major amplitud de coneixement. (Capmany a Beauvoir, 1968: 5)

$\mathrm{E}$ 11968 Maria Aurèlia Capmany obre el pròleg a l'edició catalana d'El segon sexe, de Simone de Beauvoir, amb aquestes paraules que, si en canviéssim els noms propis i alguns detalls, podrien servir per començar la seva pròpia biografia. Nascudes amb deu anys de diferència, Beauvoir el 1908 i Capmany el 1918, totes dues "privilegiades» visqueren d'entrada «en un univers ordenat», "en una família de classe mitjana, prou rica per a viure bé, prou modesta per a no haver de tenir mala consciència», foren noies de casa bona que es «desempallegaren d'aquest univers segur» i emprengueren «l'aventura de viure» d'una altra manera, exigint «de si mateixes la màxima lucidesa, la major amplitud de coneixement».

Beauvoir i Capmany, sovint comparades vitalment i intel-lectualment, compartiren i exploraren espais afins: l'existencialisme filosòfic, la literatura com a memòries personals, la crítica literària, la militància d'esquerres i el feminisme; i tot això mesclat amb una vida poc convencional. Mentre encara el discurs androcèntric regnava a Europa i es predicava la mística del matrimoni i la maternitat, francesa i catalana foren la primera generació de dones titulades que rebutjaren les ocupacions tradicionalment atribuïdes a les dones i que es llançaren a les relacions intel-lectuals i amoroses més complexes. Per moltes raons, Capmany fou la gran còmplice de Beauvoir a Catalunya. Sempre hi sentí una fonda afinitat, encara que les constants comparacions sovint l'obligaren a exclamar: "Jo no sóc Beauvoir».

En la construcció d'una genealogia femenina de la cultura, és imprescindible comptar amb «dones autoritat», "mares indiscutibles i contestades alhora», per dir-ho com Maria-Mercè Marçal, de les quals puguem poar una i altra vegada al llarg dels anys. El seu magisteri, la seva influència, el seu lideratge esdevenen punts de referència centrals per superar l'orfenesa materna crònica, tants anys sostinguda, i per sedimentar uns fonaments arqueològics sòlids, amb, si pot ser, poques escletxes, des d'on observar-les i observar-nos. Beauvoir fou una figura vertical per a Capmany, com Capmany ho fou per a Montserrat Roig, MariaMercè Marçal i tantes d'altres escriptores catalanes. Si, tal com ha mostrat el 
pare de la deconstrucció, Jacques Derrida, qualsevol autora és feta de moltes autores i molts textos perquè cap text no és original, sinó que és un text de textos, un compendi de material lingüístic i cultural divers que es multiplica i es redefineix en el temps, cal encomanar-nos la tasca de rescatar de l'oblit les mares ideològiques, en un exercici de reconstrucció de la pròpia memòria. És convenient establir xarxes intel-lectuals que ens connectin les unes amb les altres en un intent d'emmirallar-nos-hi, sia per reconèixer-s'hi, sia per revoltars'hi; en definitiva, per extreure'n forces per crear i (re)crear.

Simone de Beauvoir, una de les mares fundacionals del feminisme universal, forma part de la cultura literària mundial $i$, per extensió, de la catalana. L'objectiu d'aquest article és donar compte de la seva recepció al català, fixantnos especialment en la influència d'El segon sexe. Tenint en compte que, per diverses vicissituds, les traduccions beauvoirianes arribaren a Catalunya en dos períodes temporals separats per trenta anys de diferència, hem dividit el text en tres apartats i les conclusions. En primer lloc, analitzem la recepció de les sis primeres traduccions, totes elles de la dècada dels setanta: Una mort molt dolça (1966), El pensament politic de la dreta (febrer 1968), Les belles imatges (març 1968), El segon sexe (juny 1968), Per una moral de l'ambigüitat (juliol 1968) i La mesura de l'home (1969). En segon lloc, posem èmfasi a l'arribada d'El segon sexe i com Maria Aurèlia Capmany es convertí en l'ambaixadora de Beauvoir a Catalunya. En tercer lloc, ja al tercer mil.lenni, examinem La dona trencada (2002), l'última tradució de Beauvoir en català, i la versió abreujada d'El segon sexe, Ningú no neix dona (2009), reeditada intacta quaranta un anys després.

\section{Primera ETAPA DE TRADUCCIONS BEAUVOIRIANES}

Durant el marasme de la dictadura, els discursos dominants es ben cuidaren de negar l'entrada d'aires subversius femenins. Amb Betty Friedan, Simone de Beauvoir fou una de les primeres pensadores feministes que arribaren a Catalunya en els anys seixanta. Tanmateix, curiosament el primer producte beauvoirià que aterrà no fou una traducció de la seva obra sinó la d'una «biografia particular» de l'autora francesa. Tres anys abans de poder llegir Beauvoir en català, el 1963, l'editorial Estela publicà l'assaig Simone de Beauvoir o el fracàs d'una cristiandat, del frare dominic francès A.-M. Henry, en una traducció de l'escriptor Alfons Romeu. Col-laborador de Destino i del Diario de Tarragona, autor de Visió lírica de Tarragona (1952) o d'unes Memòries i divagacions d'un futbolista discret (1959), durant la dècada dels seixanta Romeu traduí del francès al català, per a les editorials Estela i Nova Terra, nou obres de temàtica religiosa, entre les quals destaca aquesta biografia de Beauvoir, en què s'analitza el pas del catolicisme a l'ateisme de l'autora, a partir dels seus dos primers volums autobiogràfics, Mémoires d'une jeune fille rangée i La force de l'âge.

Henry deixava clar a la introducció l'objectiu de la recerca del llibre: «L'ateisme pur, declarat, sense ambages, d'una antiga i piadosa alumna de 
l'ensenyament cristià. Com s'explica això?» (1963: 9). Tot fa pensar que l'interès del frare dominic per una autora heterodoxa respon als intents del catolicisme intel.lectual francès per assumir un protagonisme en el diàleg amb els nous corrents. Traduït al català tres anys després de la publicació original, l'escrit d'Henry sobre Beauvoir fou una de les primeres fonts per conèixer indirectament l'obra de la pensadora francesa i, d'alguna manera, posa en evidència la sensibilitat de l'església catòlica catalana per qüestions socials i polítiques d'avantguarda.

El 1966 Simone de Beauvoir s'estrenà en català amb una mostra emblemàtica: el narrador, assagista i polític Ramon Xuriguera traduí Una mort molt dolça, una obra delicada i íntima que descriu la lenta agonia de la mare de l'autora. Després de viure a París, entre 1928 i 1930, i d'exercir de professor d'espanyol a La Sorbona i de corresponsal del diari La Publicitat, Xuriguera s'inicià com a traductor, el 1934, amb Els infants terribles, de Jean Cocteau. Ja a l'exili, el 1942, traslladà El gran Meaulnes, d'Alain Fournier (encara avui inèdita). El 1943 versionà Madame Bovary, de Gustave Flaubert, la qual no sortí a llum fins al 1965. El 1966, any del seu traspàs, traduí paral-lelament dues obres simbòliques de l'existencialisme francès: La nàusea, de Jean-Paul Sartre, i Una mort molt dolça, de Simone de Beauvoir.

Sartre ja havia estat traduït al català l'any abans. Els mots, en traducció de Josep Maria Corredor, arribà a Catalunya el 1965 i fou la primera obra del filòsof francès a la nostra llengua. Després vingueren més traduccions del teatre i de l'assaig existencialista, al voltant d'una quinzena de títols, a mans de traductores i traductors rellevants com, entre d'altres, Agustí Bartra, Maria Aurèlia Capmany, Jaume Melendres, Albert Mestres, Manuel de Pedrolo, Mercè Rius, Carme Serrallonga, Bonaventura Vallespinosa i Carme Vilaginés.

Publicada dos anys després de l'original a la col-lecció "La Mirada» de l'editorial Aymà, la traducció catalana d'Una mort molt dolça, de Beauvoir, conté un pròleg en què es presenta l'autora i l'obra. Xuriguera descriu Beauvoir com «un dels valors més destacats de l'actual literatura francesa» $\mathrm{i}$ «una moralista, en el sentit de la moral existencial, la qual entén l'autentificació com un mitjà per a assolir la llibertat» (1966: 7). El traductor fa un recorregut per alguns dels quinze títols publicats fins aleshores. Destaca Linvitée, «primer llibre de Simone de Beauvoir», Tous les hommes sont mortels, «aventura metafísica que situa la gratuïtat de l'home al damunt dels esforços de l'opció», Les mandarins, que "reflecteix ja aquest domini del real empeltat al camp de la ficció», i Mémoires d'une jeune fille rangée i La force de l'âge, en què «hi senyoreja amplament» (1966: 8-9). A més, dóna fe que les reflexions sobre la condició de la dona són sempre presents en l'obra i que "hi consagra un important estudi en dos volums, Le deuxième sexe» (1966: 9). Xuriguera remarca que Beauvoir "no admet la inferioritat de la dona i confessa que ella se sent molt satisfeta de la seva entitat femenina» (1966: 9). Arribat a aquest punt, explica que l'escriptora, nascuda en un medi conformista, en el qual la família representava el món reclòs de les convencions, ensopegà sovint amb la mare. D'aquí que Una mort molt dolça, «el llibre més ric d'emoció i d'humanitat de Simone de Beauvoir», és un 
testimoni colpidor «d'un sentiment adés incomprès adés deformat i, finalment, retrobat quan la presència de la mort despulla de falsedats les comunicacions que s'estableixen entre els éssers» (1966: 10). Per acabar, Xuriguera assegura: «Fidel a la veritat, com correspon a l'ètica de l'escriptora, Una mort molt dolça és un document patètic, un testimoniatge lúcid i coratjós» (1966: 11). El pròleg no conté cap reflexió traductològica.

Després d'una breu referència de Joan Triadú sobre aquesta traducció en un article sobre el boom traductològic català dels anys seixanta a Serra d'Or el juliol de 1968, el març de l'altre any sortí a llum a la mateixa revista una crítica, signada per l'advocat i escriptor Josep Anton Baixeras, amb el títol «Tres obres de Simone de Beauvoir». Baixeras dóna la benvinguda a la primera traducció de Beauvoir: «el valor d'Una mort molt dolça, així ho creiem nosaltres, resulta indisputable» (1969: 47). Tanmateix, observa que, en ser el primer escrit de la novel-lista del qual apareix una versió catalana, facilment es pot presentar el dubte «sobre l'escaiença d'haver encetat així un conjunt tan important, a l'hora del seu anostrament» (1969: 27). Tenint en compte aquesta «escaiença», aleshores explora definicions sobre "què és un clàssic» i conclou que «el clàssic es revelaria per una referència immancable a les grans constants de l'esdevenir humà: la solidaritat, la solitud; el dolor, l'amor, la joia; el mal, la mort... » (1969: 47). En definitiva, aquest llibre de Beavoir és un clàssic que, en davallar de la tradicional abstracció a una mort concreta, la de la mare, desafia el públic lector «amb un acte d'aquells que abans en deien: obscens» (1969: 47). Baixeras hi afegeix algunes anècdotes. Sembla que Beauvoir impedí a la seva mare, catòlica, de rebre els darrers sagraments i, davant les acusacions, l'escriptora, ferida, cridà: "No va pas demanar-ho! Aquella senyora, el que volia era viure» (1969: 47). Finalment, apunta que Beauvoir deixa el públic lector inquiet perquè intueix que els prejudicis contra la mare encara hi són i, per tant, "se sent descontent i amargat». En una crítica sobre la reedició de l'obra a l'Avui del 8 de desembre de 1990, Marga Moreno també en destaca «la cruesa esfereïdora», però alhora hi afegeix que «aquesta fredor és només aparent perquè, tot i que al llarg del llibre podem trobar frases que podríem titllar de poc sentimentals o distanciades, també, mitjançant un procés d'autoanàlisi psicològica, podem veure moments colpidors en què es refereix a la relació que havia mantingut amb la seva mare».

El 1968 fou l'any de Beauvoir a Catalunya. Se'n publicaren quatre traduccions, dues de les quals a càrrec del jurista i escriptor aleshores de pensament marxista Jordi Solé-Tura. El febrer s'estrenà amb l'assaig El pensament politic de la dreta (originàriament editat a París el 1955) i el juliol continuà amb Per una moral de l'ambigüitat (originàriament editat a París el 1947), totes dues versions per a la col-lecció «jove, però prestigiada» (1969: 48), en paraules de Baixeras, de "Llibres a l'Abast», d'Edicions 62. Val a dir que el 1965 Jordi Solé-Tura ja s'havia iniciat en l'ofici de traduir amb el trasllat d'una altra obra fonamental del feminisme nord-americà, La mística de la feminitat, de Betty Friedan. Un any després, el 1966, sortia a llum La dona a Catalunya, de Maria Aurèlia Capmany, una mena de versió anostrada del clàssic de Friedan i segurament un 
dels primers textos reivindicatius sobre la qüestió feminista a l'Estat espanyol. L'editor Josep Maria Castellet fou el promotor tant de la traducció de Friedan com de l'original de Capmany.

Entre 1965 i 1970, Solé-Tura desenvolupà una breu, però intensa, activitat traductora. Sempre per a Edicions 62, traslladà trenta títols en cinc anys. Girà de l'anglès, el francès, l'italià i l'espanyol assaigs de pensament, sociologia i política afins a la seva ideologia, d'autors tan representatius com Friederich Engels, Erich Fromm, Antonio Gramsci, Herbert Marcuse, Karl Marx o Bertrand Russell. Tan sols traduí les obres de dues dones: Betty Friedan i Simone de Beauvoir. Les obres que traduí de Beauvoir, El pensament politic de la dreta i Per una moral de l'ambigüitat no incorporen cap mena de pròleg ni epíleg; tan sols la darrera inclou una nota del traductor a la pàgina 11, en què SoléTura justifica una tria traductològica: "Traduïm el verb dévoiler i el substantiu dévoilement per desvelar i desvelament, respectivament. El sentit precís amb què l'autora utilitza ambdós termes no permeten de recórrer a analogies, a expressions compostes o a mots de significació equívoca» (1968: 11).

A la primera, El pensament politic de la dreta, Beauvoir analitza la situació del pensament burgès: la teoria de l'Élite i la seva missió, la visió burgesa de la història, de la moral, del pensament i de l'art... i conclou: «La burgesia encara existeix, però el seu pensament catastròfic i buit, ja no és més que un contrapensament» (1968: 126). A la segona, Per una moral de l'ambigüitat, defensa la ideologia i l'actitud moral i intel-lectual de l'existencialisme, per mitjà d'una reflexió sobre l'ambigüitat, no en tant que la negació del sentit, sinó en tant que la no fixació i conquesta incessant. Baixeras, a "Tres obres de Simone de Beauvoir» (la traducció de Xuriguera, la segona de Solé-Tura i la d'Hermínia Grau de Duran i Carme Vilaginés d'El segon sexe) remarca que a Per una moral de l'ambigüitat Beauvoir fa una defensa «diamantina» sobre el sufragi universal «contra el qual ha estat seguida entre nosaltres una tan dilatada campanya» (1969: 48). Baixeras clou l'article amb aquesta qüestió, aleshores «actual» $\mathrm{i}$ «roent»: "L'autora creu vehementment que d'aquest acte de la voluntat en són dignes tots, i creu que per a aquest acte són aptes tots, tots: el negre i el jueu, el tècnic i el remença, la dependenta i el botiguer, el funcionari i l'emigrat..." (1968: 48).

El poeta, narrador i dramaturg Joan Oliver publicà el març de 1968 la traducció de Les belles imatges. Llicenciat en dret el 1920, Oliver s'exilià a Santiago de Xile i tornà a Catalunya el 1948. A l'exili féu algunes traduccions al castellà com a guanyapà. Ja a Catalunya, el 1973, reuní tres peces de Molière a Teatre de Molière (El banyut imaginari, El misantrop i El tartuf). A la introducció les presentava com una «refosa». També és coneguda la seva versió força lliure de l'obra de G. B. Shaw, Pigmalió (1957). Traduí teatre apassionadament: del francès, autors com Molière, Paul Claudel i Samuel Beckett; de l'italià, Carlo Goldoni i Giuseppe Berto, i, a partir de reescriptures franceses i castellanes, Anton P. Txèkhov i Bertold Brecht. A les dècades dels seixanta i setanta portà a terme diverses traduccions del francès (de vegades indirectes) d'obres de 
narrativa i d'assaig d'autors i autores contemporànies, com ara Elsa Morante, Simone de Beauvoir, Henry Miller, Jep Pascot o Eugène Ionesco.

Dos anys després que Gallimard tragués l'original a París, el 1968 Joan Oliver traduí Les belles imatges, de Simone de Beauvoir, per a la col-lecció "A Tot Vent» de l'editorial Aymà, que ell dirigia. La traducció conté un pròleg, «Simone de Beauvoir», en el qual el traductor repassa la vida i l'obra de l'escriptora francesa. En destaca que «als seus quinze anys decidí simplement i contundentment que Déu no existia», que "ha conservat al llarg de la seva joventut i la seva maduresa una certa austeritat i uns principis ètics, que provenen segurament de la seva formació burgesa», que "molt jove encara, renuncia al matrimoni i a la maternitat i opta per la cultura», que "d'aleshores ençà, viu els grans corrents del pensament francès i, amiga i deixebla predilecta de J. P. Sartre, la seva història es confon amb la de l'existencialisme francès» i, finalment, que «la nostra autora s'ha mostrat sempre profundament preocupada pel destí de la dona -el segon sexe» (1968: 5-6). Sobre la traducció, Oliver només puntualitza que "Les belles imatges és la tercera obra seva que ha estat vertida al català» (1968: 6) i dóna la referència de la primera, Una mort molt dolça, publicada per la mateixa casa editorial.

Oliver explica que aquest llibre ha estat fins a un cert punt una sorpresa per a la crítica perquè, "d'estructura senzilla», «ràpid desenvolupament» i "abundància de diàlegs», és una narració distanciada que pot significar un canvi de rumb en la producció de l'autora perquè "patentitza una pruïja de realisme que exteriorment emparenta Les belles imatges amb les novel.les burgeses d'un Henry Troyat o d'una Françoise Sagan, en les quals no trobem ni una acció dramàtica extremosa ni una anàlisi psicològica gaire aprofundida» (1968: 7). Formulada com una crítica «objectiva» de l'alta burgesia tecnòcrata, Oliver en remarca l'objectiu de l'autora: «Al capdavall, Simone de Beauvoir ha volgut, aquesta vegada, descriure -només descriure i presentar- una classe que viu apartada de la veritat i que ja no pot o no vol descobrir els valors reals dessota les aparences fictícies» (1968: 9). Tanca el pròleg amb un elogi de l'autora francesa perquè «és, dins el quefer de la creació literària, una de les ments més lúcides i més responsables del nostre temps» (1968: 9).

Un mes després de la traducció d'Oliver, el juliol de 1968, arribava El segon sexe, que tractem amb més detall a l'apartat següent. Un any i un mes després de la traducció del clàssic del feminisme, el juliol de 1969, es publicava l'assaig La mesura de l'home, de Simone de Beauvoir, en una traducció del poeta Miquel Martí i Pol. Traslladada la seva obra poètica en antologies o en volums propis a nombroses llengües, Martí i Pol s'estrenà com a traductor el $1965 \mathrm{amb}$ una novel.la d'Antoine de Saint-Exupéry, reescrita conjuntament amb Jordi Sarsanedas, a la qual seguí L'espia que m'estimava (1967), d'Ian Fleming, protagonitzada pel famós agent britànic 007. Durant més de tres dècades, sense gaires parèntesis, traduí sobretot del francès i féu petites incursions en la literatura anglesa, llatinoamericana i italiana. Del francès, girà clàssics del pensament i la literatura, com ara 
Simone de Beauvoir, Jean Genet, Jean Racine, Gustave Flaubert, Claude Lévi-Strauss o Émile Zola. Concretament, el 1969, a més de La mesura de l'home, de Simone de Beauvoir, traslladà Per una teoria de la nació, de Robert Lafont, i Tristos tròpics, de Claude Lévi-Strauss, del qual l'any següent també versionà El pensament salvatge.

Publicat a París per Gallimard el 1944, de tots els títols traduïts al català de Beauvoir fins aleshores, La mesura de l'home és el llibre que arribà amb més retard: un quart de segle. La versió catalana de Martí i Pol s'edità, com les de Solé-Tura, a la col-lecció "Llibres a l'Abast», d'Edicions 62. No duu cap paratext del traductor i el disseny de la coberta, com el de les anteriors versions beauvoirianes, compleix els objectius d'austeritat de la col-lecció. Així mateix, com en els seus altres llibres, a la contracoberta hi ha una breu descripció de l'autor i de l'obra. Se'n comenta: «Quin valor tenen els actes humans? Quina transcendència? Quina és llur mesura vàlida? Simone de Beauvoir, responent a aquestes i més preguntes, cerca un contingut a les decisions humanes, una mesura a l'acció: la mesura de l'home».

\section{EL SEGON SEXE EN CATALÀ}

Setze anys després de la traducció anglesa de l'editorial novaiorquina Bantam Books i catorze després de l'espanyola argentina de l'editorial Psique, el 1968 arribà, amb dues dècades de retard, la versió catalana d'El segon sexe, a proposta de Maria Aurèlia Capmany, que en redactà el pròleg. En foren les traductores Hermínia Grau de Duran i Carme Vilaginés. L'edició d'El segon sexe és l'única, d'entre totes les traduccions de Beauvoir a la nostra llengua, que conté una fotografia de l'autora.

D’una banda, Hermínia Grau n'enllestí el primer volum. Muller de l'historiador Agustí Duran i Sanpere, redactora d'un bon nombre d'entrades sobre música de l'Enciclopèdia Catalana, Grau traduí en els anys seixanta, dins la col-lecció «Blanquerna» d'Edicions 62, algunes obres de noms rellevants com Thomas Merton, Pierre Teilhard de Chardin, Max Thurian i Simone Weil, i el 1967 girà el Diccionari de la música de Roland Candé. D’altra banda, Carme Vilaginés en traslladà el segon. Psicòloga clínica, fundadora de l'Associació Catalana de Psicoteràpia Psicoanalítica i autora del llibre L'altra cara de l'adopció (2007), Vilaginés, entre 1965 i 1973, combinà la traducció d'algunes novel.les de Marguerite Duras, Sébastien Japrisot i Georges Simenon amb la de l'assaig filosòfic de Simone de Beauvoir i de Jean-Paul Sartre.

Òbviament, el pròleg de Maria Aurèlia Capmany, «Simone de Beauvoir, una noia de bona casa», és escrit amb passió i màxima complicitat. A "Quan les dones fumen. Maria Aurèlia Capmany - Simone de Beauvoir», de Memòria de l'aigua, Lluïsa Julià contrasta les dues escriptores i, atesos els estrets paral-lelismes, afirma que la distància mental entre elles «s'escurça notòriament, fins i tot s'esborra, situades totes dues en un context de plena contemporaneïtat» (1999: 91). 
Julià destaca que totes dues visqueren la vida intel-lectual com una dicotomia excloent que es traduïa «en primer lloc, en un rebuig explícit de les funcions tradicionalment atribuïdes a les dones el matrimoni i la maternitat, fet que provocà les crítiques de les feministes posteriors que han reivindicat el dret a la diferència; i, en segon lloc, en l'adquisició d'hàbits històricament masculins, com els pantalons en el vestir o el fumar» (1999: 91-92). De fet, com ja apunta Julià, en aquell moment l'únic camí cap al reconeixement i l'autoritat femenina passava per «remarcar els aspectes de similitud, per adaptar-se al sistema ja instaurat» $\mathrm{i}$ "paral-lelament intentar protegir la privadesa i treballar per una vida de llibertat» (1999: 92). D'aquí que en el panorama feminista català Capmany, de la mà de Beauvoir, hagi estat mare ideològica i precursora per a les generacions d'escriptores posteriors, les quals ja no s'identificaven amb les seves estratègies visibilitzadores.

A la primera part del pròleg, "Vida i obra», Capmany repassa la infantesa i l'adolescència de l'escriptora; l'abandonament de la protectora cleda familiar; l'amistat i amor per Jean Paul Sartre, "punt de referència, de judicis, d'afirmacions, de dubtes, de projectes» (1968: 7); la primera novel.la, L’invitée; el viatge a Amèrica i l'amor per Algren, o la notorietat que li proporcionà obtenir el premi Goncourt amb Les mandarins. A la segona, El segon sexe, analitza la recepció del llibre a França i breument a Catalunya.

Després d'una elaboració de dos anys i dos mesos, amb les interrupcions del viatge a Amèrica i els sis mesos que es dedicà a escriure'n les experiències, el primer volum d'El segon sexe es publicà a França el juny de 1949. El novembre del mateix any en veié la llum el segon. Des del primer moment l'obra commocionà França. "Que valenta que ets!", li va confessar una amiga. «Potser perdràs algunes amistats!», li va engegar una altra. L'autora va rebre anònims, sàtires, amonestacions, epigrames del primer sexe, i de vegades del segon, que qualificaven el llibre d'obscè i escandalós, i l'autora, d'insatisfeta, glacial, nimfòmana, lesbiana, cents vegades avortada o mare clandestina. En el pròleg, Capmany sintetitza què li van retreure:

En primer lloc l'obscenitat. No pas si la seva tesi era equivocada o incompleta, ni si els fets que citava eren verídics o no, eren les paraules, la referència al sexe, al trauma de la pubertat, a l'existència de les pràctiques d'avortament, a la insatisfacció, a les desviacions sexuals més abundants. Els mascles havien pogut repetir pudibunds durant segles la tesi tota mulier in utero, el llatí els privava d'enrojolar-se; però que la intel-ligència d'una dona s'inclinés amb objectivitat i ordre sobre uns fets que ningú no podia negar era més del que els honorables prohoms i dames podien suportar. (1968: 17)

El segon sexe és un punt de referència obligat per al pensament feminista occidental. La idea preeminent del llibre recolza la teoria construccionista del subjecte. La dona no neix, es crea. Seguint l'ètica existencialista que marcarà tota la seva obra, Beauvoir defensa que la identitat femenina és una construcció històrica fruit d'unes condicions materials. Contrària a les teories que sostenen que hi ha una essència femenina estable i universal, anterior al propi discurs 
sobre la feminitat i fora dels límits socials i, per tant, fora de l'ordre patriarcal, Beauvoir desconfia de qualsevol tret específic de la dona. Capmany resumeix les dues parts del llibre:

Tot el primer volum: Els fets $i$ els mites és la recerca del fonament històric i biològic d'aquesta alteritat. L'ésser humà no és una espècie natural, sinó una espècie històrica; ara, la dona és la contrapartida d'aquesta especificació, la seva naturalesa és el resultat de la qualificació que en fa el mascle. Tot analitzant els fets i els mites, Simone de Beauvoir descobreix no sols la determinació de l'ésser dona, des de la visió masculina, sinó la constant d'aquesta visió en l'exposició, classificació i interpretació dels fets que l'home científic comenta. En el segon volum, aparegut el novembre del mateix any, titulat L'experiència viscuda, planteja, en les coordenades de l'estudi precedent, la realitat de la dona d'avui. Des de la infancia a la maduresa, en la funció de mare i en la funció social, la dona apareix com un ésser partit entre allò que la realització plena de la seva personalitat li reclama i allò que la vigència del mite de l'alteritat li imposa. (1968: 16)

A Elsegon sexe Beauvoir es basa en les idees sobre les estructures de parentiu de l'antropòleg Lévi-Strauss, les quals no li feren més que confirmar la seva teoria: «La humanitat és mascle i l'home defineix la dona no en si, sinó relativament a ell; la dona no és considerada com un ésser autònom. [...] Ella es determina i es diferencia en relació amb l'home i no aquest en relació amb ella; és l'inessencial davant l'essencial. Ell és el Subjecte, és l'absolut: ella és l'Altre» (1968: 24). El segon sexe no és un llibre optimista quant al destí del sexe femení. Malgrat creure que la majoria de conflictes de les dones desapareixeran amb el socialisme i la fi del patriarcat, Beauvoir sosté que la determinació psicoanalítica les condiciona enormement i que en la majoria dels casos les dones s'identifiquen abans amb la classe social o la raça que el sexe. Tanmateix, segons Beauvoir, el pitjor de tot és que, per molt que guerregin i aconsegueixin nous propòsits, lluiten sempre contra rellotge i la seva història depèn molt més que la de l'home del seu destí fisiològic.

Malgrat el missatge difícil, de vegades ambigu, El segon sexe és un dels millors llibres feministes de tota la literatura feminista. A partir d'aleshores, i més concretament els últims quinze anys de la seva vida, Simone de Beauvoir, per dir-ho com Deirdre Bair, «...que havia passat la major part de la vida en grups d'homes, centrada en les preocupacions polítiques de Sartre, se sentí més a gust en situacions que hagués de compartir la seva experiència amb dones» (1990: 554). Ben aviat es convertí en la «mare espiritual» del feminisme de l'època. Capmany recull aquesta idea quan afirma que la publicació del text en català al cap de vint anys després de l'original francès «revela més que cap altra proposició demostrativa la vigència del mite» (1968: 17).

Quan s'edità el 1949, El segon sexe passà totalment desapercebut en territori català, per raons polítiques evidents. A més, en aquella època, com apunta Capmany, a la dona catalana «li era reservada una alta missió: donar fills a la pàtria» (1968: 18). Continua lamentant-se: «La mística de la feminitat, havia fet ja la seva feina i havia destruït ràpidament tota l'obra que mig segle d'educació liberal havia intentat, molt feblement, aconseguir» (1968: 18). Els 
diaris del país no es dedicaven a elogiar o a criticar el paper de la dona en el treball, sinó que publicaven amb orgull els projectes de subsidis familiars que ajudarien la dona a no treballar fora de casa. Van haver de passar uns quants anys perquè aquesta obra arrelés en les noves generacions. Capmany tanca el pròleg amb aquestes paraules: «El segon sexe arriba avui, al cap de vint anys, a un nou clima: l'aventura d'aquesta traducció ens en dóna la prova. Una nova joventut té tendència a dir les coses pel seu nom i a no esborronar-se. Tant de bo aquest llibre sigui útil per al segon sexe i també per al primer» (1968: 18).

Baixeras dedica la meitat de «Tres obres de Simone de Beauvoir» a El segon sexe. Com Capmany, acaba remarcant la utilitat del llibre i expressant el desig de què sigui profitós «als nostres homes i dones» (1969:48). A l'inici, Baixeras, com no fa amb cap dels altres dos llibres comentats, fa referència a la traducció, deixant-se, però, el nom de la traductora del segon volum:

En una eficaç traducció d'Hermínia Grau de Duran, que manté el ritme de reportatge, crepitant, contundent, peculiar en l'autora, i dins una col-lecció que, ja d'antuvi, amb el seu títol genèric, ens barra el pas devers una crítica de valor (és la "Biblioteca Bàsica de Cultura Contemporània”, d'Edicions 62), surten els dos volums de l'assaig de Simone de Beauvoir El segon sexe. (1969: 47)

Per a ell, El segon sexe és «una obra d'aquelles que diuen de capçal», «una assaigmatriu, l'empremta del qual copsarem encara, em sembla, en altres productes de l'intel.lecte contemporani, àdhuc sobre temes allunyats, durant anys» (1969: 47). També es fixa en el fet que, des de la seva publicació a França, s’hagin escolat vint anys: «L'autoritat del temps, respectant el llibre, forneix, doncs, un altre argument per a obligar-nos a posar-lo, obedients nosaltres al rètol emfatic de la col-lecció i a la devoció de la prologuista, al prestatge principal dels vigents i dels models» (1969: 47-48). Baixeras es deixa encomanar per la devoció de la prologuista i es desfa en arguments per esbrinar, amb exemples, «si al sud dels Pirineus el problema presenta modes específics de manera que adopti formes d'especial virulència». I conclou: «I creiem efectivament, i en això, almenys, devem anar d'acord amb la prologuista de l'obra, que és que sí» (1969: 48).

Traduïts El segon sexe i alguns assaigs polítics molt lligats al context ideològic de revolta i de descoberta d'autors i autores dels anys setanta, malauradament s'inicia un silenci traductològic beauvoirià que durarà més de tres dècades.

\section{Segona etapa De traduccions beauvoirianes}

Ja al nou mil.lenni, trenta-tres anys després de la traducció de Martí i Pol, el 2002, es publicà La dona trencada, en una traducció de la poeta, assagista i traductora Marta Pessarrodona. La dona trencada consta de tres narracions que reflecteixen tres fracassos personals: "L'edat de la discreció", "Monòleg» i «La dona trencada». A l'article «Tres dones», de l'Avui del 17 d'octubre de 2002, Susanna Rafart apunta que són «obres de tesi» amb voluntat pedagògica: «Beauvoir no fa concessions, i la prosa amb què basteix el trencament és 
tan cantelluda com el món que s'hi explica». Davant les diverses habilitats tècniques amb què Beauvoir encara cadascuna de les històries, Rafart elogia aquesta versió: «La traducció és eficaç i aconsegueix donar la varietat formal que exigeixen els textos. Es tracta d'una llengua poc marcada i que segurament modernitza el caràcter d'escola de la versió original». També saluda la voluntat de l'editorial Deriva «de prendre partit per la traducció literària de la mà de plomes tan sòlides» com la de Marta Pessarrodona.

L’original s'edità a França el 1967. Aquí arribà amb gairebé quatre dècades de retard i és l'últim títol traduït de Beauvoir. El volum es presenta sense paratextos, malgrat que Pessarrodona sovint prologa les seves traduccions o les d'altres. Prolífica poeta i autora de diversos retrats d'escriptores catalanes, cal destacar-ne la feina com a assagista i divulgadora d'obres d'autores i autors anglesos i nord-americans, especialment del grup de Bloomsbury i de temes feministes. Amb una llarga i consolidada trajectòria com a traductora, ha girat de l'anglès i del francès al castellà obres de Louis Althusser, Quentin Bell, Marie Cardinal, Lewis Carroll, Leonore Fleischer, E. M. Foster, Janet Frame, Lillian Hellman, W. H. Hudson, Erica Jong, Doris Lessing (diversos títols), Sylvia Plath, Dora Russell, Susan Sontag, Claire Tomalin, John Updike o Leonard i Virginia Woolf. Al català, ha traslladat menys títols, dels quals destaquen noms d'autores rellevants per als estudis de gènere: des de Gertrude Stein, Marguerite Duras i Françoise Sagan, traduïdes abans d'acabar el segle, fins a Simone de Beauvoir, Susan Sontag i Virginia Woolf, traduïdes a l'inici d'aquest nou. En el centenari del naixement de l'autora francesa, a l'Avui del 18 de gener de 2008, Pessarrodona recordava i elogiava El segon sexe, ja que «va ser, és i serà un llibre fonamental», alhora que declarava que haver pogut traduir La dona trencada li havia fet canviar la seva percepció de la Beauvoir com a literata: «hi vaig detectar un desig d'estil del qual, enamorada de la memorialista i de l'assagista, no m'havia adonat».

Des d'una declarada voluntat de recuperació i de divulgació genealògiques, el 2009 la col-lecció «Capsa de Pandora», d'Eumo Editorial, publicava Ningú no neix dona, una antologia de textos d'El segon sexe, en la traducció intacta, de fa quaranta un anys, d'Hermínia Grau i Carme Vilaginés i una presentació de l'acadèmica i escriptora Marta Segarra. L'elecció de recuperar la traducció dels anys seixanta comporta dues qüestions estratègiques: d'una banda, converteix el text en una joia canònica; de l'altra, reafirma la feina de les traductores en relació amb el conjunt de la tradició traductològica catalana. Segurament el seu valor sorgeix de la intersecció d'aquests dos factors. A «Re-translation», Isabelle Vanderschelden argumenta, a partir de les nocions "primera traducció» i «millor traducció» d'Antoine Berman, que la «primera traducció» és una traducció «that is not necessarily contemporaneous with the publication of the original, but which represents a first attempt at translating a given literary work» (Classe, 2000: 1155). Optar per recuperar la primera traducció d'El segon sexe de Beauvoir al català porta implícit una tria política, de reconeixement al mestratge, la innovació i la grandesa que va aportar en aquell moment a la nostra cultura la introducció de l'autora i el text, amb la complicitat de la prologuista 
i les traductores. Ja vindran temps per a retraduccions d'El segon sexe a la nostra llengua. En el cas anglès, tot i les constants crítiques que ha merescut al llarg del temps la "primera traducció» del text de Beauvoir, han trigat cinquanta-set anys en aconseguir-ho, del 1953 al 2010, i sembla que la "segona traducció» també ha suscitat múltiples debats i discòrdies, dignes de seguir però que que no tractarem aquí. Esperem que en el cas català, si es donen les circumstàncies de retraduir el text, anem més ràpid $\mathrm{i}$ ho fem amb més consens.

Quant al pròleg de Ningú no neix dona, Segarra el divideix en quatre parts. A «Simone de Beauvoir, filòsofa, escriptora i feminista», presenta el personatge, a qui descriu com la «mare del feminisme» i, la relació amb Sartre, com «una família no biològica, composta per amics i amigues que els van envoltar fins a la mort, no sense conflictes i ruptures» (2009: 8). A «Gènesi i composició d'El segon sexe», inscriu l'assaig en el gènere de les «obres autobiogràfiques o d'introspecció». Atès que es tracta d'una obra de més de mil pàgines «amb una voluntat gairebé enciclopèdica», Segarra justifica oportú «fer-ne una tria de fragments» i n'explica els criteris: d'una banda, parts representatives del conjunt que continguin reflexions sobre la condició de les dones que encara puguin ser considerades actuals; de l'altra, la introducció i la conclusió, així com capítols sencers "per tal de reflectir l'estil de Simone de Beauvoir» (2009: 9). Tenint en compte que Beauvoir fa un repàs de la història de la humanitat en un intent de cercar el moment que es va instaurar la desigualtat entre homes i dones, Segarra afirma que aquesta part d'El segon sexe «inaugura, en certa manera, la disciplina que poc després s'anomenarà 'història de les dones', les accions de les quals oblida o minimitza normalment la historiografia tradicional» (2009: 11). En tercer lloc, a l'apartat "El segon sexe i el pensament feminista", qualifica "de molt variada» la recepció del llibre, tant a França, als Estats Units com a Europa en general, com també entre el mateix moviment i pensament feministes. Com a mare contestada del feminisme, sovint se l'ha acusat «de menysprear els valors que serien pròpiament femenins» $\mathrm{i}$ "d'assumir una posició masculina». Finalment, a «L'obra de Simone de Beauvoir al món català i hispànic», repassa en general la recepció de l'obra de Beauvoir a la península ibèrica. Segarra conclou: «En definitiva, no podem obviar la lectura d'El segon sexe si ens interessa la situació material i simbòlica de les dones en el món d'ahir, d'avui i de demà» (2009: 20).

Per acabar aquest panorama de les traduccions de Simone de Beauvoir al català, cal tenir en compte les trajectòries afins que comparteixen els traductors i les traductores: la majoria són escriptors i escriptores rellevants de la literatura catalana, un perfil normal en els anys seixanta i setanta en què, amb la «liberalització» de la censura franquista, una gran part de la intel-lectualitat compaginava les dues feines. Els casos de Joan Oliver i Marta Pessarrodona, de generacions ben diferents, resulten paradigmàtics d'aquests paral-lelismes; en l'un i l'altra l'obra traductològica va influir en la literària i a l'inrevés. Mentre que per a Jordi Solé-Tura fou un ofici concentrat en cinc anys, el mitjà de vida entre 1965 i 1970 (després no tornà a traduir mai més), per a Martí i Pol fou un guanyapà tota la vida. Per a Ramon Xurriguera fou el darrer 
projecte traductològic abans de morir. Per a Hermínia Grau i Carme Vilaginés esdevingué una comesa col-lectiva puntual, única. Mai més compartiren cap traducció i a partir de la dècada dels vuitanta, quan sorgí la primera generació de traductores professionals, totes dues deixaren l'ofici de traduir i es dedicaren a altres tasques culturals. En general, a unes motivacions d'admiració per l'obra i la figura de Beauvoir, s'hi ha d'afegir la voluntat de donar-la a conèixer en la nostra llengua, sense deixar de banda la qüestió econòmica.

$\mathrm{Al}$ costat dels punts assenyalats aquí, caldria examinar altres aspectes de les traduccions de Beauvoir, com ara la metodologia emprada, la ideologia implícita que traspuen o l'anàlisi de característiques variades de les mateixes traduccions (lingüístiques, sociolingüístiques o de gènere, entre d'altres). Al capdavall, estudiar la "Beauvoir traduïda» és una altra manera de subratllar la continuïtat de la seva presència entre nosaltres.

\section{Conclusions}

A manera de conclusió, com a «mare indiscutible i contestada alhora», Simone de Beauvoir ha suscitat passions i contestacions arreu. En terres catalanes, però, segurament ha tingut més públic adepte que detractor. Cal destacar dos moments clau en la repercussió de Beauvoir a Catalunya: l'aterratge frondós dels seixanta i el tímid ressorgiment del tercer mil.lenni. El primer va coincidir amb un període de bonança i boom editorial. Les vicissituds històriques, socials i culturals del país alimentaren l'interès per la seva obra política, existencialista i feminista. El segon l'inicià Marta Pessarrodona el 2002 quan ressuscità el mite. La seva traducció i la reedició el 2009 de parts d'El segon sexe responen a la voluntat persistent de persones i col-lectius feministes de continuar excavant per recuperar noms i obres desateses pel cànon dominant. Coincidint el 2008 amb el centenari del seu naixement, aquest ressorgiment beauvoirià va anar acompanyat d'articles, jornades i congressos, exposicions, posades en escena, com l'adaptació teatral de La dona trencada per Iraida Sardà, i algun assaig monogràfic, com Em sento estafada. Una lectura de Simone de Beauvoir (2010), d'Araceli Bruch. Tot aquest material demostra que l'obra de la Beauvoir feminista encara és vigent a Catalunya.

Malgrat que el pensament existencialista de Jean-Paul Sartre ha caigut en un cert oblit en el món cultural europeu ${ }^{2}$, val a dir que en el context català s'ha anat traduint d'una manera continuada (no ha passat cap dècada sense versionar-se'n alguna obra). Per contra, traduïda a vastament en els anys seixanta i obviada durant les tres dècades finals del segon mil.lenni, Simone de Beauvoir

2. Octavi Martí reconeixia a El País el 18 de juny de 2005, en ocasió de la celebració del centenari del seu naixement, que els mateixos francesos no sabien què fer-ne: "Comunista, fumador, bebedor, adicto al Corydane, Sartre es irrepetible. Nadie se atreve a hacérselo suyo, ningún partido ni bando le quiere porque el tipo y su obra son mucho más ricos que nuestro actual pensamiento débil y consensual, y el uno y la otra están atravesados por más contradicciones de las que ningún heredero es capaz de asumin. 
és sobretot recordada per la seva vessant feminista i per un text, El segon sexe. Hi atribuïm dues raons: d'una banda, perquè, en comptar amb una ambaixadora del nivell de Maria Aurèlia Capmany, l'obra beauvoiriana ha format part del substrat ideològic de la majoria d'escriptores catalanes dels setanta en endavant; de l'altra, perquè les filles ideològiques catalanes de Beauvoir han sabut valorar la necessitat de mantenir la seva presència viva, reconeixent-la com una avantpassada dins la tradició literària femenina i incorporant, ja sigui per alabar o contestar, les seves teories en els propis escrits. Simone de Beauvoir és, sens dubte, una de les mares per excel.lència dels feminismes d'avui. En el cas català, la traducció hi ha jugat un paper discret.

\section{Bibliografia}

Bacardí Montserrat, «Ramon Xuriguera i la traducció», URC. Revista Literària, no 23, septembre 2008, p. 66-72.

Bacardí Montserrat, Godayol Pilar (dir.), Diccionari de la traducció catalana, Vic, Eumo, 2011.

Bartrina Francesca, «La crítica literària feminista a Catalunya en els darrers trenta anys», Literatures, no 3, 2005, p. 89-102.

Bair Deirdre, Simone de Beauvoir. A biography, London, Vintage, 1990.

Benach Joan-Anton, «Trágica y cursi», La Vanguardia, 1 mars 2008, p. 46.

Baixeras Josep A., «Tres obres de Simone de Beauvoir», Serra d'Or, no 114, mars 1969, p. 47-48.

Bruch Araceli, Em sento estafada. Una lectura de Simone de Beauvoir, Tarragona, Arola, 2010.

Classe Olive, "Re-translation», dins Olive Classe (ed.), Encyclopedia of Literary Translation into English, Londres, Fitzroy Dearborn, p. 1154-1155.

Godayol Pilar, «Maria Aurèlia Capmany, feminisme i traducció», Quaderns. Revista de Traducció, n 14, 2007, p. 11-18.

Henry A-M., Simone de Beuvoir o el fracàs d'una cristiandat, Barcelona, Editorial Estela, 1963. [Trad. Alfons Romeu]

Julià Lluïsa, "Quan les dones fumen. Maria Aurèlia Capmany - Simone de Beauvoir», dins Lluïsa Julià (ed.), Memòria de l'aigua. Onze escriptores i el seu món, Barcelona, Proa, 1999, p. 90-121.

Martí Octavi, «Francia no sabe qué hacer con Sartre», El Pais. Babelia, 18 juin 2005, p. 3-4.

Moi Toril, Simone de Beauvoir. The making of an intellectual woman, Cambridge, Blackwell, 1994.

Moreno Marga, "Simone de Beauvoir, entre la fredor i la tendresa», Avui Cultura, 8 décembre 1990, p. 11.

Pessarrodona Marta, "Quan érem beauvoirianes», Avui, 18 janvier 2008, p. 28.

Rafart Susanna, «Tres dones», Avui, 17 octobre 2002, p. XI. 
Showalter Elaine, Mujeres rebeldes. Una reivindicación de la herencia intelectual feminista, Madrid, Espasa Calpe, 2002. [Trad. Inés Belaustegui]

Triadú Joan, «Novel-la estrangera en català. Després d'una generació sense traduccions», Serra d'Or, n 106, mars 1968, p. 39-41.

\section{Traduccions de Simone de Beauvoir al català}

Beauvoir Simone de, Una mort molt dolça, Barcelona, Aymà, 1966. [Pròleg i traducció de Ramon Xuriguera]

- El pensament politic de la dreta, Barcelona, Edicions 62, 1968. [Traducció de Jordi Solé-Tura]

— Les belles imatges, Barcelona, Aymà, 1968. [Pròleg i traducció de Joan Oliver]

- Per una moral de l'ambigüitat, Barcelona, Edicions 62, 1968. [Traducció de Jordi Solé-Tura]

— El segon sexe. I i II, Barcelona, Editorial 62, 1968. [Pròleg: Maria Aurèlia Capmany. Traducció d'Hermínia Grau de Duran i Carme Vilaginés]

- La mesura de l'home, Barcelona, Edicions 62, 1969. [Traducció de Miquel Martí i Pol]

- La dona trencada, Barcelona, Deriva, 2002. [Traducció de Marta Pessarrodona]

- Ningú no neix dona. Antologia de textos d'El segon sexe, de Simone de Beauvoir, Marta Segarra (ed.), Vic, Eumo, 2009. [Pròleg de Marta Segarra. Traducció d'Hermínia Grau de Duran i Carme Vilaginés] 